\title{
Effect of Structure and Texture on Failure of Pipe Steel Sheets produced by TMCP
}

\author{
M. L. Lobanov ${ }^{1,2}$, S. V. Danilov ${ }^{1}$, V. I. Pastukhov ${ }^{1,3}$, I. Yu. Pyshmintsev ${ }^{4}$, and \\ V. N. Urtsev ${ }^{5}$ \\ ${ }^{1}$ Ural Federal University, 19 Mira St., Yekaterinburg, Russia \\ ${ }^{2}$ Institute of Metal Physics, Ural Branch of RAS, $18 \mathrm{~S}$. Kovalevskoi St., Yekaterinburg, Russia \\ ${ }^{3}$ JSC "Institute of Nuclear Materials", Zarechny, Sverdlovsk Region, Russia \\ ${ }^{4}$ OJSC "RosNITI", 30, Novorossiysk St., Chelyabinsk, Russia, \\ ${ }^{5}$ Ausferr Research and Technology Center, 18 Gorkogo St., Magnitogorsk, Russia
}

\section{Abstract}

The method of orientation microscopy (EBSD) is used to study the structure and texture of low-carbon, low-alloy pipe steel sheets processed by controlled thermomechanical processing (TMCP). The temperatures of isothermal hot rolling varied. Samples cut from sheets showed a different fracture tendency during mechanical testing. The formation

Corresponding Author:

S. V. Danilov

bs.v.danilov@bk.ru

Received: 25 February 2019

Accepted: 9 April 2019

Published: 15 April 2019

Publishing services provided by

Knowledge E

(c) M. L. Lobanov et al. This

article is distributed under the

terms of the Creative Commons

Attribution License, which

permits unrestricted use and

redistribution provided that the

original author and source are

credited.

Selection and Peer-review under the responsibility of The Ural school-seminar of metal scientists-young researchers Conference Committee. of cleavages (secondary cracks) during failure of steel is related to the presence of ferrite grains with orientation $\{001\}<110>$ extended in the hot rolling direction. The formation of grains is a consequence of the isothermal hot rolling below the temperature $\mathrm{A}_{c 3}$ at TMCP.

Keywords: pipeline steel, thermo-mechanical controlled processing, bainite, ferrite, cleavage, orientation microscopy (EBSD), texture.

\section{Introduction}

An increase in working pressure as a result of using high-strength steels is one of the most promising ways of increasing the economic efficiency of main gas pipelines located in complex climatic conditions. The obvious advantage of using high-strength pipes is a reduction in metal content (pipe wall thickness). The breakthrough in improvement of structural strength of low-alloy pipe steels occurred in the middle of the 1970s in view of the development and introduction into industrial production of thermomechanical controlled processing (TMCP) combining controlled rolling and subsequent controlled cooling [1-3].

Research in recent years has shown that a feature of bainitic steels of strength classes S OPEN ACCESS 
bending, static crack resistance tests) of secondary cracks, i.e., separations, propagating perpendicular to the main crack plane. It is important to note that separations are observed in contemporary large diameter pipes with ductile crack propagation $[4,5]$. On the example of contemporary pipe steels with low contamination by inclusions and quite uniform microstructure, it has been demonstrated that cleavages are caused by features of microstructure formed during sheet treatment [4, 5], which determines their strict orientation along the rolling direction (RD). In [6], reasons for forming cleavages in high-strength pipe steels with a bainitic structure, low content of carbon and harmful impurities are also connected with preferred crystallographic texture. In the destruction of pipe steel sheets, an important role is played not by the integral texture but by a single weak component (001)[110], as shown in [7-10]. Crack development depends on the presence of extended regions with consistent orientation over a distance exceeding the critical crack size.

In the present work, we investigate the formation of structural and textural states (bainite, ferrite) in sheets of low-carbon, low-alloy pipe steel obtained by TMCP depending on isothermal hot rolling temperatures.

\section{Research Methods}

We investigate sheet samples (depth $27 \mathrm{~mm}$ ) of 06Г2MБ low-carbon, low-alloy pipe steel, containing $0.06 \mathrm{wt} \% \mathrm{C}, 1.7 \mathrm{wt} \% \mathrm{Mn}, \sim 0.05 \mathrm{wt} \% \mathrm{Nb}$, and $\sim 0.05 \mathrm{wt} \% \mathrm{Mo}$, (The remainder is Fe and unavoidable impurities). The isothermal hot rolling temperatures $\left(\mathrm{T}_{i H R}\right)$ of steel sheets made up $\sim 840^{\circ} \mathrm{C}$ (State I) and $\sim 760^{\circ} \mathrm{C}$ (State II).

Calculations of phase thermodynamic equilibria were carried out using ThermoCalc software. The calculated steel $A_{c 3}$ was equal to $830^{\circ} \mathrm{C}$.

The TMCP steel sheets were cut along the RD for mechanical testing. Tests have demonstrated a marked difference between modes I and II (Table 1).

TABLE 1: Mechanical properties of the samples of low-carbon low-alloy steels.
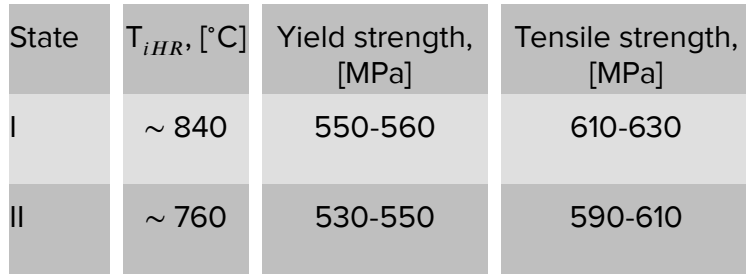

\begin{tabular}{|l|}
\hline$\delta_{5},[\%]$ \\
\hline 23.5 \\
\hline 24.5
\end{tabular}

$\mathrm{KCV}_{-60}$,
$\left[\mathrm{J} / \mathrm{cm}^{2}\right]$
$380-$
400
$360-$
380

$\mathrm{KCV}_{-40}$,
$\left[\mathrm{J}_{\mathrm{cm}}^{2}\right]$
$350-$
380
$300-$
340

Tendency to
cleavage
not
observed
observed

Metallographic sections are prepared from the steel samples in plane defined by the direction of rolling in TMCP and the normal to the rolling plane. The sample structure is investigated electron microscopically by means of a ZEISS CrossBeam AURIGA scanning 
microscope (with an accelerating voltage of $20 \mathrm{kV}$ ). To determine the orientation of individual grains and analyze the local texture, we use an EBSD HKL Inca attachment with an Oxford Instruments analytical system. The scanning increment is $0.1 \mu \mathrm{m}$. The error in determining the lattice orientation is no more than $\pm 1^{\circ}$ ( $\pm 0.6^{\circ}$ on average). Small angle boundaries between the local volumes are plotted on orientation charts when the disorientations are $2-7^{\circ}$ and $8-15^{\circ}$; the boundary thickness in the graphics is 1 and 2 pixel. Large-angle boundaries between the local volumes are plotted on orientation charts when the disorientation exceeds $15^{\circ}$; the boundary thickness in the graphics is 3 pixels. The texture is investigated by plotting orientation distribution functions (ODF). Analysis of the special boundaries between individual grains involves plotting such boundaries on orientation charts, in the light of the standard Brandon criterion $\pm \Delta \Theta$ in the software. For each boundary, $\left.\Delta \Theta=15^{\circ} / \Sigma n\right)^{1 / 2}$, where $\Sigma n$ is the number of coinciding points when three dimensional crystal lattices are superimposed.

In orientation analysis, the laboratory system adopted is the coordinate system whose axes are, respectively, parallel to the direction of hot rolling (DR) in TMCP (X IDR), to the normal (ND) to the rolling plane (YIIND), and to the perpendicular direction (PD) that runs along the roller axis (ZIIPD). Accordingly, these three directions form a right triad of vectors.

\section{Results and Discussion}

In the samples I with bainite structure after TMCP (Fig. 1, a), we observe extended regions that run in the direction of rolling (thickness 5-35 $\mu \mathrm{m}$ ). These regions correspond to austenite grains deformed by controlled rolling. They have taken on bainite structure as a result of $\gamma \rightarrow \alpha$ transition. Presumably, the dimensions of the regions corresponding to the initial austenite grains are retained on account of the formation of disperse carbides at the boundaries in hot deformation [1]. In the samples II after TMCP (Fig. 1, b), we observe extended regions with practically parallel boundaries that run in the direction of rolling (thickness 5-25 $\mu \mathrm{m}$ ). Elongated ferrite phase grains (thickness to $5 \mu \mathrm{m})$ were observed in the samples II after TMCP along the boundaries of the initial deformed $\gamma$-grains (Fig. 2, b). This ferrite can be identified as high temperature $\alpha$-phase existed in steel by isothermal hot rolling. Some $\alpha$-grains were fragmented. They had time recrystallization.

All large-angle boundaries are concentrated with disorientations of $49-60^{\circ}$ (Fig. 1, c, d). In the spectra of special boundaries observed in all structures, boundaries of the coincidence site lattices (CSL): $\Sigma 3, \Sigma 11, \Sigma 17 \mathrm{~b}, \Sigma 25 \mathrm{~b}, \Sigma 33 \mathrm{c}$, and $\Sigma 41 \mathrm{c}$ are the most strongly 


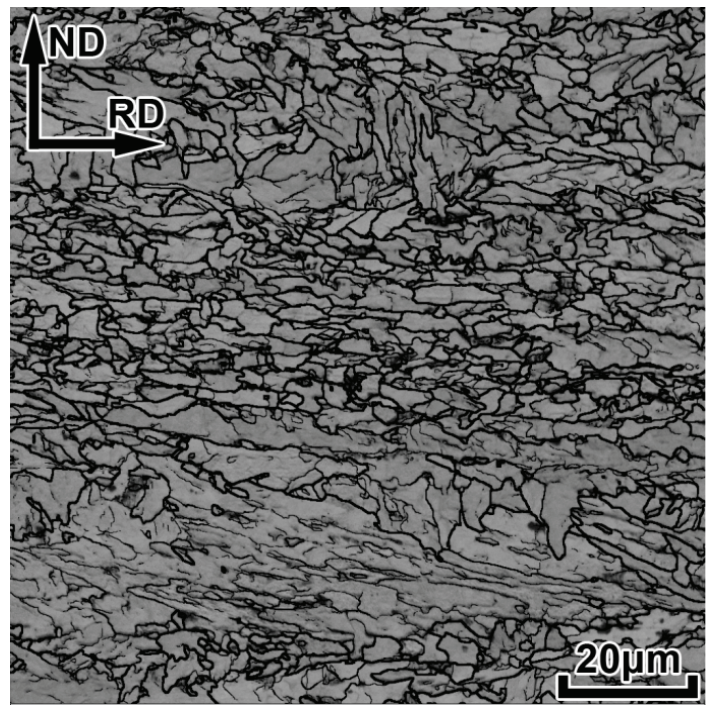

a
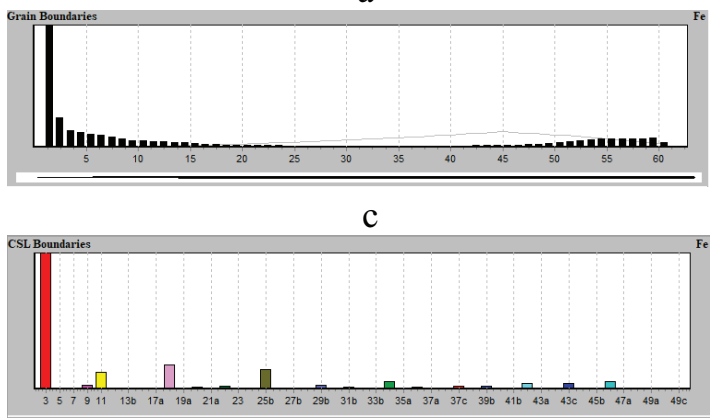

$\mathrm{e}$

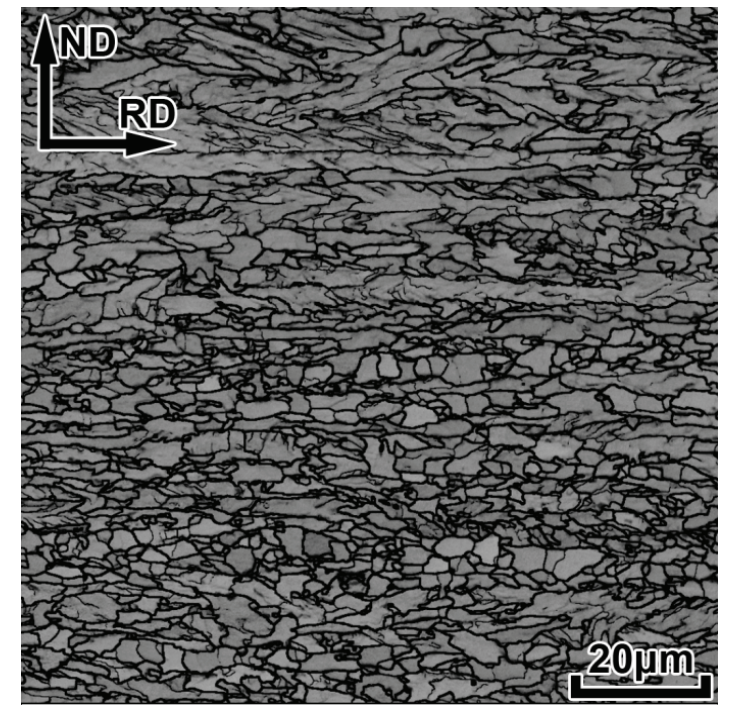

b

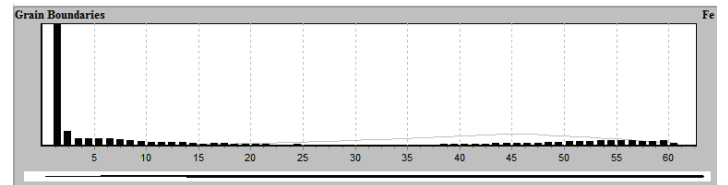

d

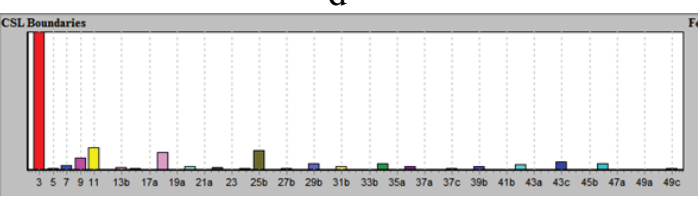

$\mathrm{f}$

Figure 1: The microstructure of the steel in the TMCP states in the form of orientation maps (EBSD) - band contrast and intercrystalline boundaries: $a, c$, e - I-840 state; b, d, f - II-760 state; c, d - distribution of intercrystalline boundaries; e, $\mathrm{f}$ - distribution of CSL boundaries.

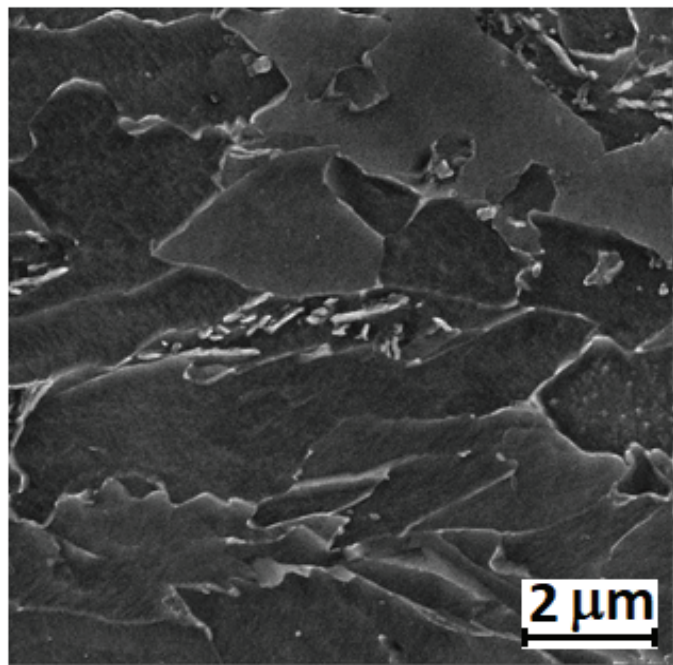

a

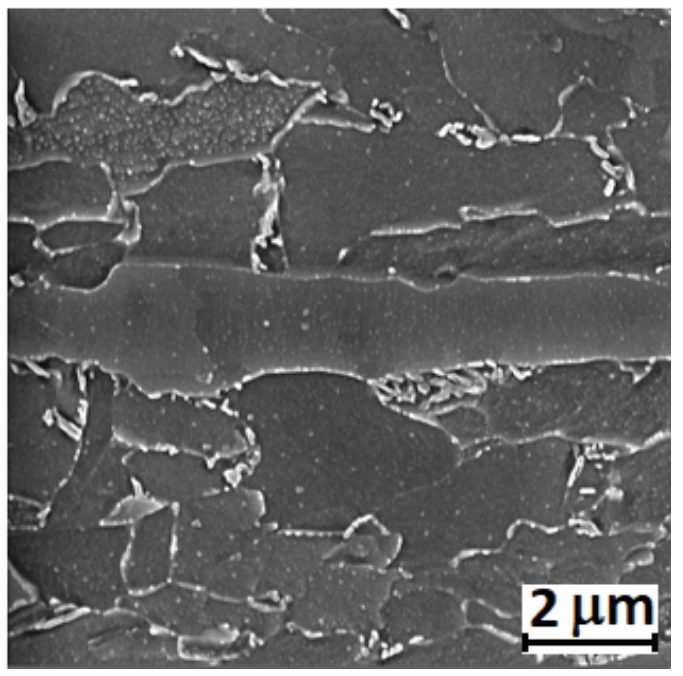

b

Figure 2: The microstructure of the steel in the TMCP states (image in backscattered electrons): a $-1-840$ b - II-760.

expressed (Fig. 1, e, f). This spectrum is the result of shear phase transformation, in 
accordance with orientation relations intermediate between the Kurdjumov-Sachs and Nishiyama-Wasserman types, as shown in [11]. Such spectra of special boundaries are also seen in the martensite of low-carbon pipe steel [12, 13].

EBSD data show that the texture of all the samples consists mainly of the same scattered components: very strong (001)[110] orientations, two $\sim\{112\}\langle 110\rangle$ orientations, and two $\sim\{110\}<223>$ (Fig. 3). In the samples II the (001)[110] orientation and the $\{112\}<110>$ orientations expressed more strongly (Fig. 3, c, e). The main orientations correspond to relatively uniform regions consisting of crystallites separated by small-angle boundaries.

The applied orientational EBSD technique allowed to define the structurally ferrite in the samples II and analyze the texture. All indicated orientations of the ferrite formed at hot rolling, namely: $\{001\}<110\rangle,\{11 \mathrm{k}\}<110\rangle$, are stable deformation orientations of the BCC lattice [14]. It should be noted that, taking into account the crystal-geometric characteristics of structurally ferrite (orientation, shape and size of grains), it can be considered as a kind of "macro defect". Propagation of longitudinal cracks will be predetermined in the crystallographic planes $\{001\}$ of elongated ferrite grains $[7,10]$.

Obviously, the elongated ferritic grains formed during isothermal hot rolling at temperatures below $A_{c 3}$. It is also obvious that they are the cause of reduction in mechanical properties.

\section{Summary}

The formation of cleavages the destruction of low-carbon low-alloy steel pipe with a bainitic structure obtained controlled thermo-mechanical treatment, due to the presence in the material of the crystallographic texture components (001)[110] and $\{11 \mathrm{k}\}<110>$. The elongated ferritic grains the region with uniform orientation of the $(001)<110>$ and $\{11 \mathrm{k}\}<110>$ formed during isothermal hot rolling by TMCP at temperatures below $A_{c 3}$.

\section{Acknowledgements}

The work was carried out using the laboratory equipment "Structural methods of analysis and properties of materials and nanomaterials" of the Center of Ural Federal University. The work has been carried with the support of the Russian Science Foundation, grant No. 19-79-20006. Authors are grateful for the assistance the program of support for leading universities in Russian Federation for improvement of their competitiveness №211 of the Government №02.A03.21.0006. The authors thank MMK company for support and assistance in organizing the study. 

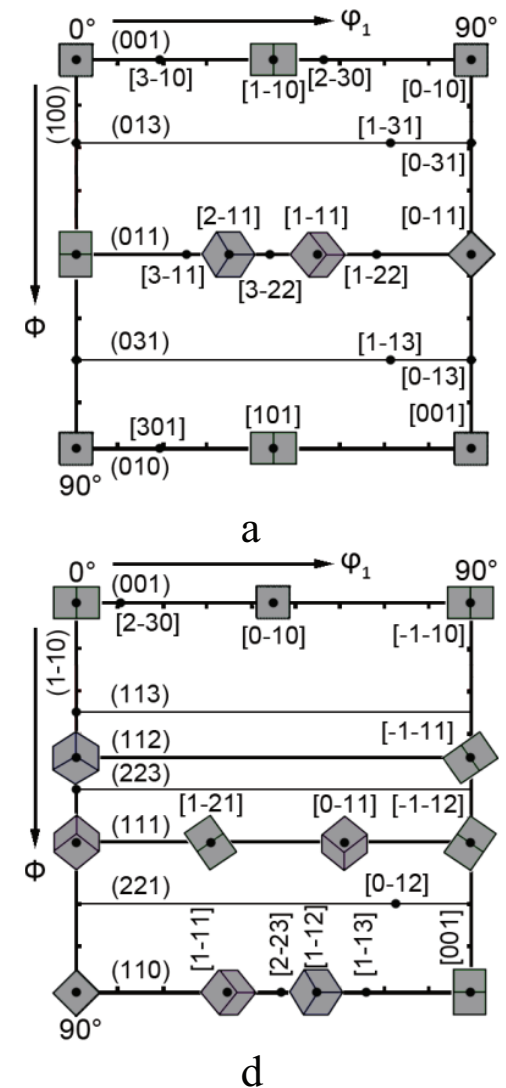

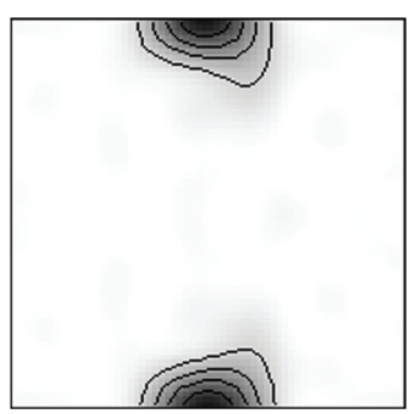

$\mathrm{b}$

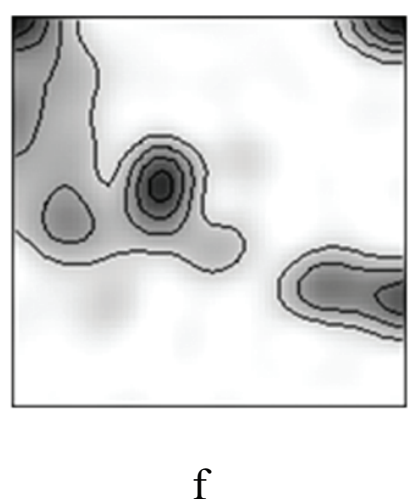

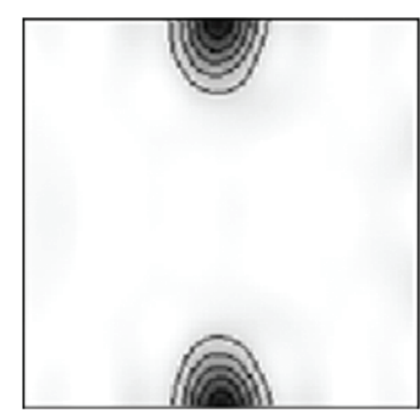

$\mathrm{c}$

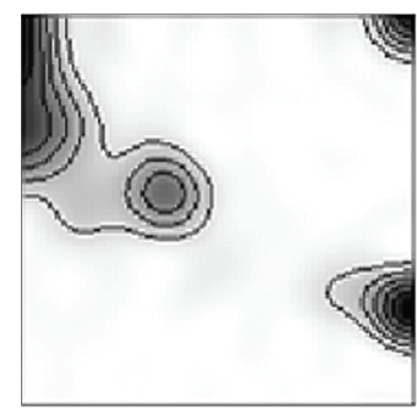

$\mathrm{e}$

Figure 3: The texture of the steel in the TMCP I-840 (a, b) and II-760 states (c, d) as ODF sections: a, c, e sections $\varphi_{2}=0^{\circ} ; \mathrm{b}, \mathrm{d}, \mathrm{f}-$ sections $\varphi_{2}=45^{\circ} ; \mathrm{e}, \mathrm{f}-$ schematic orientations from the direction perpendicular to the RD-ND plane.

\section{References}

[1] K. Hulka, P. Peters, F. Haisterkamp, Trends in the development of large-diameter pipe steels, Steel Transl. 27, No. 10 (1997) 64-70.

[2] M.-Sh. Zhao, K. Yang, Y. Shan, The effects of thermo-mechanical control process on microstructures and mechanical properties of a commercial pipeline steel, Mater. Sci. Eng. A, 335 (2002) 14-20.

[3] S. Endo, N. Nakata, Development of Thermo-Mechanical Control Process (TMCP) and high performance steel in JFE Steel. JFE Technical Report, 20 (2015) 1-7.

[4] G. Mannucci, G. Demofonti, Control of ductile fracture propagation in X80 gas line pipe, Thesis Proc. Int. Pipeline Technology Conf., Beijing, China, (2010) 412.

[5] I.Yu. Pyshmintsev, A.M. Mal'tseva, A.M. Gervas'ev, et al., Structure and properties of low-carbon steels subjected to pneumatic tests, Stal, No. 2 (2011) 75-81.

[6] T. Hara, Y. Shinohara, H. Asahi, and Y. Terada, Effects of microstructure and texture on DWTT properties for high strength line pipe steels, Proc. 6th IPC2006, Calgary, Alberta, Canada (2006). 
[7] I.Yu. Pyshmintsev, A.O. Struin, A.M. Gervas'ev, et al., Effect of bainite crystallographic texture on failure of pipe steel sheets made by controlled thermomechanical treatment, Metallurgist, 60, No. 3-4, (2016) 405-412.

[8] I.Yu. Pyshmintsev, A.M. Gervasyev, R.H. Petrov, et al., Crystallographic texture as a factor enabling ductile fracture arrest in high strength pipeline steel, Mater. Sci. Forum, 702-703 (2012) 770-773.

[9] M.A. Mohtadi-Bonab, M. Eskandari, and J.A. Szpunar, Texture, local misorientation, grain boundary and recrystallization fraction in pipeline steels related to hydrogen induced cracking, Mater. Sci. Eng., A, 620 (2014) 97-106.

[10] S.V. Danilov, E.R. Struina, and M.D. Borodina, Splitting of pipe steel produced by TMCP, Steel Translation, 47, No. 3 (2017) 188-189.

[11] M.L. Lobanov, G.M. Rusakov, A.A. Redikul'tsev, et al., Research of special boundaries in lath martensite of low-carbon steel by orientation microscopy, Phys. Met. Metallogr. 117, No 3 (2016) 254-259.

[12] A.I. Stepanov, I.N. Ashikhmina, K.I. Sergeeva, et al., Structure and properties of lowalloy Cr-Mo-V steel after austenitization in the intercritical temperature range, Steel Translation, 44, No. 6 (2014) 469-473.

[13] M.L. Lobanov, M.D. Borodina, S.V. Danilov, et al., Texture Inheritance on Phase Transition in Low-Carbon, Low-Alloy Pipe Steel after Thermomechanical Controlled Processing, Steel Translation, 47, No. 11 (2017) 910-918.

[14] M. Hölscher, D. Raabe, and K. Lücke, Relationship between rolling textures and shear textures in f.c.c. and b.c.c. metals, Acta Metallurgica et Materialia 42, No 3 (1994) 879_ 886.

[15] I.U. Pyshmintsev, I.N. Veselov, A.A. Yakovleva, et al., Evolution of the texture of lowcarbon microalloyed pipe steel in the seamless pipe manufacturing process, MRDMS 2016, AIP Conference Proceedings, 1785 (2016) 040053. 